\title{
Percursos de autoria de licenciandos em Letras da Universidade do Estado do Amazonas (UEA)/Lábrea-AM
}

\section{Courses of Authorship of graduating in Letters of the University of the State of Amazonas (UEA)/Lábrea-AM}

\author{
Antonio Paulino dos Santos \\ Instituto Federal de Educação, Ciência e Tecnologia do Amazonas \\ paulinoventura.labrea@gmail.com \\ Amarildo Menezes Gonzaga \\ Instituto Federal de Educação, Ciência e Tecnologia do Amazonas \\ amarildo.gonzaga@yahoo.com.br
}

\section{Resumo}

Este artigo tem o objetivo de apresentar os resultados obtidos com a aplicação do Produto Educacional "Percurso de Autoria: Enxergando-se autor da própria história", curso de curta duração com carga horária de 40 horas, oriundo da dissertação "Percursos de Autoria de Professores no Ensino Tecnológico", cujo objetivo geral é criar mecanismos para que o cursista compreenda a importância de seu percurso de autoria para o ressignificar das práticas pedagógicas, a partir da reflexão de seus episódios marcantes, enxergando-se autor da própria história. Tal produto foi aplicado a 8 (oito) licenciandos do curso de Licenciatura em Letras do Centro de Estudos Superiores da Universidade do Estado do Amazonas (UEA) de Lábrea-AM, o que culminou com a escrita de narrativas autobiográficas, oportunidade em que percebeu-se a autoria de suas próprias histórias, com traços particulares, advindos das experiências vivenciadas nos aspectos: pessoal, acadêmico e profissional.

Palavras-chave: Autobiografia. Prática pedagógica. Professor-autor.

\section{Abstract}

This article aims to present the results obtained with the application of the Educational Product "Courses of Authorship: Looking at the author of his own history" short course of 40 hours from the dissertation "Courses of Authorship of Teachers in Technological Teaching" whose general objective is to create mechanisms so that the cursist understands the importance of his course of authorship to the re-signification of the pedagogical practices from the reflection of its remarkable episodes seeing himself as the author of the story itself. This product was applied to 8 (eight) graduates of the graduating degree in Letters of 


\section{Educitec \\ ISSN: $2446-774 X$}

the Center for Higher Studies of the University of the State of Amazonas (UEA) of Lábrea-AM which culminated in the writing of autobiographical narratives, an opportunity in which the authorship of their own histories was perceived, with particular traits, resulting from the experiences lived in the personal, academic and professional aspects.

Key words: Autobiography. Pedagogical practice. Teacher-author.

\section{Apresentando o Produto Educacional "(Per)curso de Autoria: Enxergando-se Autor da própria história"}

Durante a realização do Mestrado Profissional em Ensino Tecnológico no IFAM campus Manaus Centro sempre foi uma preocupação minha a execução daquilo que viria a ser o produto educacional do curso, porém, o que me tranquilizou nesse processo foi a ingente experiência do meu orientador, o prof. Dr. Amarildo Menezes Gonzaga, que em suas abordagens declarava constantemente que "[...] não há a necessidade de você se preocupar desesperadamente em busca de um produto educacional porque o transcorrer da pesquisa indicará qual será o produto de sua dissertação". Sábias palavras!

Essa realidade começou a mudar quando em julho de 2017 (período 2017/2) viajei a Lábrea para realizar pesquisa de campo com os professores do IFAM campus Lábrea. Executar uma Roda de Conversa em que os mesmos contariam suas histórias e como se enxergavam professores do IFAM, em Lábrea. Estudo do referencial teórico-metodológico, planejamentos das ações, roteirização das atividades etc.

Foi uma experiência única e naquele momento, a partir de tudo o que fora exposto pelos professores partícipes da Roda de Conversa, surgia o insight para o produto da minha dissertação: um curso de curta duração de 40 horas intitulado "(Per)curso de autoria: enxergando-se autor da própria história". Meu orientador estava corretíssimo (como sempre!). O andamento da pesquisa me fez enxergar o produto educacional: uma investigação que transformaria o percurso do pesquisador em Produto Educacional da dissertação.

Era momento de transcrever todas as vivências e experiências perpassadas com as atividades da pesquisa de modo a fazê-las convergir para um modelo de produto com o objetivo geral de "[...] compreender a importância do percurso de autoria para o ressignificar das práticas pedagógicas, a partir das reflexões dos episódios marcantes do cursistas [professores ou não], enxergando-se autor da própria história".

Tal objetivo foi estabelecido porque "[...] nossa própria existência não pode ser separada do modo pelo qual podemos nos dar conta de nós mesmos. É contando nossas próprias histórias que damos, a nós mesmos, uma identidade" (PAUL RICOUER, 1994) e, contumaz,

[...] as lembranças e reminiscências mais significativas e representativas da nossa história pessoal, acadêmica e profissional se fazem importantes pela possibilidade que inauguram de darmos 


\section{Eteducitec \\ ISSN: $2446-774 X$}

sentido à nossa trajetória e projetarmos uma direção ao que ainda pretendemos construir e experimentar como profissionais da educação. [CUNHA, 2007, p. 69].

Dessa forma, o curso foi estruturado em três eixos fundamentais, conforme Sandín Esteban (2010, p. 29-30), abordando as dimensões ontológica, epistemológica e metodológica, de modo a tornar essencial a importância do cursista se colocar na origem do seu dizer, trazendo à tona seu contexto histórico-social; a forma com a qual conversa com referenciais teóricos consolidados e qual sua linha de atuação, além de como trilha seus caminhos no processo investigativo, definindo o percurso a seguir em seus estudos.

Os eixos estruturantes, objetivos específicos e conteúdos abordados no nosso curso, são apresentados na Quadro 1.

Quadro 1 - Eixos estruturantes do Curso

\begin{tabular}{|c|c|c|c|}
\hline EIXOS $\rightarrow$ & ONTOLÓGICO & EPISTEMOLÓGICO & METODOLÓGICO \\
\hline $\begin{array}{l}\text { OBJETIVOS } \\
\text { ESPECÍFICOS } \rightarrow\end{array}$ & $\begin{array}{l}\text { Conhecer os } \\
\text { cursistas }\end{array}$ & $\begin{array}{l}\text { Compreender os } \\
\text { conceitos básicos da } \\
\text { Autoria }\end{array}$ & $\begin{array}{l}\text { Discutir a utilização de } \\
\text { mecanismos para } \\
\text { formalização de um } \\
\text { percurso }\end{array}$ \\
\hline CONTEÚDOS $\rightarrow$ & $\begin{array}{l}\text { - Episódios } \\
\text { marcantes da } \\
\text { trajetória pessoal, } \\
\text { acadêmica e } \\
\text { profissional; } \\
\text { - Projetos } \\
\text { desenvolvidos; } \\
\text { - Como se veem } \\
\text { sendo } \\
\text { professores; }\end{array}$ & $\begin{array}{l}\text { - A importância da leitura } \\
\text { e da escrita. } \\
\text { - Autor e autoria; } \\
\text { - Professor-pesquisador; } \\
\text { - Narrativas; }\end{array}$ & $\begin{array}{l}\text { - Fundamentos da } \\
\text { pesquisa em } \\
\text { Educação; } \\
\text { - Pressupostos da } \\
\text { Pesquisa; } \\
\text { - Roda de Conversa; } \\
\text { - Portfólio; }\end{array}$ \\
\hline
\end{tabular}

Fonte: Adaptado de SANTOS; GONZAGA (2017, p.17).

Para melhor entendimento da Quadro 1, elaboramos a Quadro 2 em que são elaboradas as temáticas centrais e os conteúdos a serem estudados em cada eixo estruturante, haja vista que o curso foi concebido para ser aplicado em 5 dias de 4 horas cada, totalizando 20 horas de atividades em encontros presenciais e outras 20 horas em atividades complementares, perfazendo 40 horas de (per)curso.

Quadro 2 - Roteirização do (per)curso (continua)

\begin{tabular}{|c|c|c|c|c|}
\hline $\begin{array}{l}\text { DI } \\
\text { A }\end{array}$ & EIXOS & $\begin{array}{l}\text { TEMÁTICA } \\
\text { CENTRAL }\end{array}$ & CONTEÚDO & $\begin{array}{c}\text { ATIVIDADES } \\
\text { COMPLEMENTAR }\end{array}$ \\
\hline 1 & Ontológico & $\begin{array}{l}\text { Iniciando o } \\
\text { navegar }\end{array}$ & $\begin{array}{l}\text { - Apresentação: } \\
\text { Individual; } \\
\text { - Dinâmica: Troca de um } \\
\text { segredo; } \\
\text { - Vídeo: Saúde mental } \\
\text { dos pós-graduandos, de } \\
\text { Robson Nascimento - TV } \\
\text { UFMG; } \\
\text { - Texto: Leitura e Escrita: } \\
\text { dois capítulos desta } \\
\text { história de ser educador } \\
\text { (Soligo e Prado). }\end{array}$ & $\begin{array}{l}\text { - Ler e fichar o texto: Projeto } \\
\text { de trabalho que foi virando } \\
\text { um projeto de Pesquisa } \\
\text { (Edith Chacon Theodoro); } \\
\text { - Escrever sobre um projeto } \\
\text { marcante, desenvolvido em } \\
\text { sala de aula; }\end{array}$ \\
\hline
\end{tabular}




\section{Ededucitec \\ iss $246-5,72 x$}

\begin{tabular}{|c|c|c|c|c|}
\hline \multicolumn{5}{|c|}{ Quadro 2 - Roteirização do (per)curso (conclusão) } \\
\hline 2 & $\begin{array}{l}\text { Epistemoló } \\
\text { gico }\end{array}$ & $\begin{array}{l}\text { Desbravan } \\
\text { do os } \\
\text { caminhos } \\
\text { da Autoria }\end{array}$ & $\begin{array}{l}\text { Texto 1: O percurso da } \\
\text { autoria (Borges e } \\
\text { Moreira); } \\
\text { Texto 2: Sobre o } \\
\text { (RE)conhecimento da } \\
\text { Pesquisa do Professor: } \\
\text { prosa e poesia (Cunha e } \\
\text { Prado); } \\
\text { Texto 3: A tendência } \\
\text { professor-pesquisador em } \\
\text { um percurso de autoria } \\
\text { (Santos e Gonzaga). }\end{array}$ & $\begin{array}{l}\text { - Ler e fichar o texto: Conte- } \\
\text { me agora - As narrativas } \\
\text { como alternativas } \\
\text { pedagógicas na pesquisa e } \\
\text { no ensino (Maria Isabel } \\
\text { Cunha) } \\
\text { - Escrever sobre o seu } \\
\text { percurso de autoria, } \\
\text { enaltecendo aqueles mais } \\
\text { marcantes de sua vida } \\
\text { pessoal, acadêmica e } \\
\text { profissional. }\end{array}$ \\
\hline 3 & $\begin{array}{l}\text { Metodológic } \\
\text { o }\end{array}$ & $\begin{array}{l}\text { Diferentes } \\
\text { formas de } \\
\text { construir } \\
\text { um } \\
\text { caminho }\end{array}$ & $\begin{array}{l}\text { Texto: Modos de (o)usar } \\
\text { (SANTOS, 2016, p. } 118 \text { e } \\
\text { seguintes). O que é um } \\
\text { portfolio? Conceitos, } \\
\text { modelos e aplicações. } \\
\text { Portfolios online (...) } \\
\text { Vídeo 1: Como criar seu } \\
\text { portfolio/blog no Wix; } \\
\text { Vídeo 2: Tutorial Kawek. }\end{array}$ & $\begin{array}{l}\text { - Pesquisar sobre os } \\
\text { diferentes tipos de Portfólios, } \\
\text { inclusive os modelos online; } \\
\text { - Ler o capítulo } 3 \mathrm{da} \\
\text { dissertação: O Ensino por } \\
\text { meio da Literatura de } \\
\text { Cordel (SANTOS, 2016). }\end{array}$ \\
\hline 4 & - & $\begin{array}{l}\text { (Re)constru } \\
\text { indo a } \\
\text { própria } \\
\text { história }\end{array}$ & $\begin{array}{l}\text { Oficina pedagógica para a } \\
\text { construção de um } \\
\text { Portfólio online, } \\
\text { descrevendo o percurso } \\
\text { de autoria, a partir da } \\
\text { trajetória pessoal, } \\
\text { acadêmica e profissional, } \\
\text { em consonância com o } \\
\text { narrado nos encontros } \\
\text { presenciais. }\end{array}$ & $\begin{array}{l}\text { - Concluir a construção do } \\
\text { Portfólio online. }\end{array}$ \\
\hline 5 & & $\begin{array}{l}\text { Socializand } \\
\text { o a } \\
\text { produção }\end{array}$ & $\begin{array}{l}\text { Portfolio online para } \\
\text { divulgação. }\end{array}$ & $\begin{array}{l}\text { - Seminário de apresentação } \\
\text { dos Portfólios para o público } \\
\text { externo e interno. }\end{array}$ \\
\hline
\end{tabular}

Fonte: Adaptado de SANTOS; GONZAGA (2017, p. 18).

Independente da normatização apresentada, o curso não é estático, mas pode (e deve) ser adaptado para outras realidades, seja para qualquer modalidade de ensino, para públicos diferenciados e até mesmo para realização individual. $O$ que sugerimos é que seja mantido o referencial teórico apresentado, a partir do exposto e dos Planos de Curso e Roteiros de Estudos, que podem ser acessados através do link: $<$ https://drive.google.com/file/d/1MRtVyleTcOeCLWB8SBSpSxuyDkRSR8HZ/vi ew>.

Apresentamos a seguir a aplicação deste Produto Educacional, inclusive com os materiais e métodos utilizados, junto aos licenciandos do Curso de Licenciatura em Letras, da Universidade do Estado do Amazonas (UEA), Centro de Estudos Superiores de Lábrea. 


\section{Ededucitec \\ ISSN: $2446-774 X$}

\section{Aplicando o (Per)curso aos licenciandos em Letras da UEA/Lábrea e o passo-a-passo das atividades}

Após a entrega da versão final da minha dissertação junto à Coordenação do Mestrado Profissional em Ensino Tecnológico, ocorrida em 15 de janeiro de 2018, concluía oficialmente tal curso. Era momento de apreender que "[...] o caminho percorrido não se torna um fim, mas um meio para os outros percursos que ainda virão." (GONZAGA; ANIC, 2017, p. 14-15).

Oportunidade ideal de retornar à Lábrea para colocar em prática todo 0 aprendizado logrado, as vivências e experiências partilhadas, a fim de (com)partilhar com os conterrâneos toda a riqueza de conhecimento obtida, gerando novos conhecimentos, projetos, estudos e o mais importante, retribuir à sociedade todo o investimento em mim depositado. Reiterando ainda que "[...] o mais importante mesmo não é chegar, mas permanecer navegando, fazendo do trajeto o destino e do destino um lugar imaginário que garante a essencialidade do processo investigativo, qual seja, a permanente busca" (GHEDIN; FRANCO, s/d, p. 2).

Essa contextualização me fez optar por aplicar inicialmente o Produto Educacional no Ensino Superior de Lábrea, na turma de Licenciatura em Letras, haja vista que a Autoria encontra fundamentação na leitura/escrita e cenário mais oportuno não haveria do que este. Ademais, a temática do Produto é imprescindível para que os acadêmicos tenham um contato direto com uma pesquisa stricto sensu na área de Educação, o que perpassará aos mesmos fundamentação teórico-metodológica para a realização de seus trabalhos de conclusão de curso.

Iniciei os trâmites legais, em 05 de fevereiro de 2018, apresentando a proposta de aplicação do Produto ao Diretor Geral do Centro de Estudos Superiores da UEA, em Lábrea, senhor Raimundo Nonato Duarte Amâncio. Este prontamente atendeu a solicitação, disponibilizou sala de aula e todo o aparato tecnológico para a execução do curso e me apresentou à professora assistente do curso de Letras, a senhora Arlene de Almeida Nascimento.

A professora informou que o curso de Letras é ofertado através do Sistema Presencial Mediado por Tecnologia (o IPTV), cujas aulas são planejadas e ministradas em estúdio de televisão, em Manaus e retransmitidas a 30 municípios pela Internet (inclusive a Lábrea), sendo que a mesma acompanha as aulas e interage com os professores titulares na capital, por meio do sistema de videoconferências, chats, fóruns, e-mails, a fim de esclarecer as dúvidas dos acadêmicos além de outros aspectos para a execução do ensino-aprendizagem. O curso está iniciando o $6^{\circ}$ período letivo $(2018 / 1)$ e tem previsão de término para ao mês de agosto de 2019 e conta atualmente com 36 dos 42 acadêmicos matriculados.

O período 2018/1 teve início no dia 20 de fevereiro de 2018 e no dia seguinte, após autorização do Diretor da UEA/Lábrea e da professora Assistente do curso de Letras divulguei minha pesquisa aos 36 acadêmicos. Apresentei a proposta do curso de curta duração de 40 horas para a turma. Não especifiquei o quantitativo de vagas ou certificação para não condicionar a participação a um 


\section{aEducitec \\ ISSN: 2446-774X}

determinado retorno. A intenção sempre foi a de que a participação neste (per)curso seria para o desenvolvimento pessoal e profissional destes, sem preocupação exacerbada com certificado de atividades complementares e suas nuances.

Após vários questionamentos e sugestões ficou estabelecido o cronograma do curso. Seria ofertado durante cinco (5) sábados, das $14 \mathrm{~h}$ às $18 \mathrm{~h}$, totalizando 20 horas de encontros presenciais $(03,10,17$ e 24 de março e 07 de abril de 2018) na Sala 3 da UEA/Lábrea e as demais 20 horas (de atividades complementares) realizadas durante a semana e apresentadas no sábado seguinte. Inscreveramse 17 dos 35 acadêmicos da turma. Segue, o passo-a-passo das atividades desenvolvidas.

\section{a) Iniciando o navegar (1ㅇ dia - 03/03/2018);}

O primeiro momento do primeiro dia de curso foi dedicado à apresentação individual dos acadêmicos, onde narraram suas expectativas quanto ao curso, suas características, as vivências na graduação, dificuldades na academia, dentre outros. Ato contínuo foi proposta a dinâmica "Troca de um segredo", em que foram motivados a escrever sobre seus problemas, dilemas ou dificuldades que estavam vivenciando no momento. Após a escrita, embaralhou-se os papeis recebidos e entregues um para cada participante, com a missão de propor resolução para o problema, dilema ou dificuldade do colega, sem saber de quem era esse problema.

Essa atividade apontou como principais dificuldades: a distância dos familiares; o pouco tempo para realizar as tarefas na graduação; problemas para definição do tema do trabalho de conclusão de curso; desemprego; morte repentina de entes queridos e drogadição na família. Destaque considerável para 0 desemprego, haja vista que a $75 \%$ deles estão desempregados. Após debates, foi apresentado como solução: conversa com amigos; organização do tempo; revisão às disciplinas estudadas; qualificação e realização de cursos; orações e busca por grupos de autoajuda.

A segunda atividade do dia foi a Leitura Dialogada do artigo "Leitura e Escrita: dois capítulos dessa história de ser educador", de Rosaura Soligo e Guilherme do Val Toledo Prado (2007), onde os acadêmicos leram blocos de textos e iam apresentando suas considerações. Após conhecerem mais sobre a história da leitura e escrita, foram convidados, através de uma roda de conversa, a contar como se deu seu processo quanto à leitura e à escrita. Episódios, personagens, reminiscências. Finalizada a roda, foi proposta a atividade complementar para a semana: a leitura do artigo "Projeto de trabalho que foi virando um Projeto de Pesquisa", de Edith Chacon Theodoro (2007) e solicitada a escrita detalhada de um projeto marcante que o licenciando realizou (ou que gostaria de realizar) como professor (para entrega no próximo encontro).

\section{b) Desbravando os caminhos da Autoria (2 dia - 10/03/2018);}

A dimensão debatida nesse encontro foi a epistemológica, na qual os cursistas assimilaram os conceitos básicos relacionados à Autoria, através da realização de uma estratégia metodológica conhecida como Diálogo Sucessivo. O grupo foi 


\section{Ceducitec \\ ISSN: 2446-774X}

dividido, num primeiro momento, em três subgrupos. Cada subgrupo realizou leitura, técnicas de sublinhado, esquema e resumo de um determinado artigo: (i) O percurso da autoria (BORGES; MOREIRA, 2004); (ii) Conte-me agora: as narrativas com alternativa pedagógica na pesquisa e no ensino (CUNHA, 1997) e (iii) A tendência professor-pesquisador em um percurso de autoria (SANTOS; GONZAGA, 2017).

Concluído os estudos iniciais dos artigos, o grupo foi reorganizado de forma que cada subgrupo foi composto por um cursista que estudou cada artigo. Dessa forma, o representante explicou seu artigo estudado aos demais e foi por eles avaliado quanto à (i) clareza, (ii) síntese, (iii) coerência, (iv) segurança e (v) Argumentação. E assim os demais integrantes do subgrupo também o fizeram, de modo que o mesmo grupo teve uma visão geral de cada um dos artigos indicados, por isso a atividade é denominada Diálogo Sucessivo (os debates se sucedem à maneira que cada integrante do grupo apreende acerca de todos os artigos estudados).

Posso afirmar que a atividade foi bem aceita pelos cursistas tanto pelo aprendizado adquirido quanto pela dinamicidade. É algo que eles manifestaram interesse em implementar nos seus projetos atuais, no estágio supervisionado e posteriormente como profissionais da Educação.

Como última atividade do dia foi realizada Roda de conversa sobre o percurso de autoria dos cursistas. Os mesmos foram convidados a refletir sobre seus episódios marcantes de vida pessoal, acadêmica e profissional porque

[...] Em suma, [...] percursos de autoria são os episódios marcantes ocorridos na vida pessoal, acadêmica e profissional da pessoa e, quando por elas refletidos repercutem para a ressignificação de suas práticas (sejam pedagógicas ou não), possibilitando novos olhares (novas escritas) a determinadas formas de caminhar. (SANTOS, 2017, p. 166).

Os acadêmicos contaram sobre suas origens; o início na escola; o incentivo dos pais e outros familiares aos estudos; as dificuldades para concluir o Ensino Médio e posteriormente para ingressar na graduação. Como atividade complementar, foi solicitada a transcrição e complementação da narrativa de cada cursista.

\section{c) Diferentes formas de construir um Caminho (3 dia - 17/03/2018);}

O terceiro dia de curso tinha como objetivo a utilização de mecanismos para a formalização de um percurso e a ideia original era o estudo acerca de Portfólio, com conceitos, modelos diversos (manuais, online, etc), aplicações e exposição de vídeos de como criar um portfolio através dos tutoriais Wix e Kawek.

Durante a explanação inicial percebi que, já objetivando o Colóquio final do curso, devido as inúmeras atividades que os acadêmicos vinham enfrentando na graduação, principalmente quanto ao Estágio Supervisionado e por não terem experiência como professores, redirecionei o objetivo deste encontro, bem como os demais, quanto à importância da Narrativa (Auto)biográfica dos mesmos.

Nesse sentido, fizemos apenas uma revisão geral acerca do Portfolio e direcionamos os esforços para a Narrativa (Auto)biográfica, aproveitando que os 


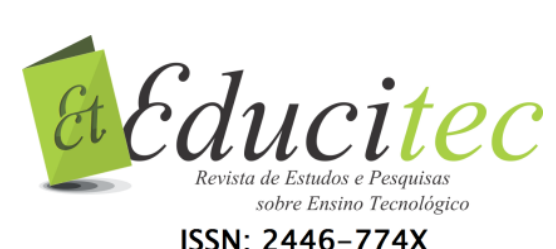

ISSN: $2446-774 X$

mesmos já tinham iniciado a escrita narrativa de seus percursos na aula anterior e, inclusive, deveriam complementá-la durante a semana. Ato contínuo explanei sobre a minha narrativa (auto)biográfica registrada no primeiro capítulo da dissertação "Percursos de Autoria de Professores no Ensino Tecnológico".

Os mesmos fizeram questionamentos sobre o escrito e avaliaram positivamente a comparação que fiz entre o meu percurso de autoria e o caminho realizado pelo Rio Purus desde a nascente, no Peru, até sua foz, no encontro com o Rio Solimões.

$\mathrm{Na}$ parte final do encontro, realizou-se a leitura da narrativa "As histórias e influências de um mestrando do Ensino Tecnológico no Amazonas", de Marden Eufrásio dos Santos (extraída de: GONZAGA, 2015, p. 285-293) e solicitado como atividade complementar que os cursistas finalizassem suas narrativas $e$ organizassem uma prévia da apresentação final para o próximo encontro.

\section{d) (Re)construindo a própria História (4ํ dia - 24/03/2018);}

No penúltimo encontro, conforme definido no sábado anterior, foi organizada uma prévia da apresentação das narrativas, visando o Colóquio de Narrativas, última atividade do curso, em que os mesmos apresentariam suas narrativas (auto)biográficas.

O primeiro momento foi dedicado às prévias e cada cursista expôs de forma sucinta sua narrativa. Emoções, surpresa, dedicação e histórias de luta e superação foi possível observar nos relatos. E o visível crescimento no curso de cada um dos narradores. Ao final do momento, definimos como seria o Colóquio de Narrativas, a ordem das apresentações, dentre outros.

E assim, devidamente macomunados para a atividades final definiu-se como atividade complementar que cada cursista definisse a sua forma própria de apresentação, constando de exposição pura e simples, através de música, poema, etc. O importante era manifestar seus percursos através da narrativa.

\section{e) Socializando a produção (5 DIA - 07/04/2018).}

Na pós-graduação stricto sensu percebe-se a importância da leitura e da escrita já que o trabalho final desta modalidade de ensino culmina com a escrita de uma dissertação, ademais é necessário dar destaque à socialização das nossas publicações, pois o conhecimento gerado deve ser colocado à disposição dos pares para ser confirmado ou refutado, o que gerará novos conhecimentos. Por isso, após 4 semanas de (per)curso com os acadêmicos do Curso de Letras da UEA/Lábrea é essencial que seja dada publicidade às suas construções, às suas narrativas.

Iniciamos o último dia de atividades com o registro fotográfico executado por José Rodrigues da Silva e com a avaliação escrita acerca do (per)curso de autoria de cada cursista, em que os mesmos apresentaram suas considerações. A importância de participarem ativamente de um Produto Educacional de uma pesquisa de Mestrado; de todo o aprendizado galgado a partir da experiência do (per)curso; das lembranças e reminiscências resgatadas; da possibilidade que o (per)curso oportunizou para que estes ressignifiquem suas práticas e moldem- 


\section{Eteducitec \\ ISSN: 2446-774X}

se melhor como profissionais da Educação; da essencial identidade docente que tanto urge a Educação de Lábrea e que é realidade durante o caminhar; da necessidade de se constituírem multiplicadores dessa prática, dentre outros aspectos relevantes que foram lembrados pelos partícipes.

No momento seguinte, os cursistas finalistas (8 dos 17 inscritos) entregaram suas narrativas impressas e preparam-se para o Colóquio Final. Organizamos previamente o espaço, que funcionou como cenário e cada um, a sua vez, fez a explanação de sua narrativa: (i) Geovane Alves de Paiva, (ii) Bruno Henrique de Souza, (iii) Jailton Santos de Oliveira, (iv) Antonio José Rodrigues Cordeiro e (v) Roseli Roberto de Lima. Salientamos que (i) Keliane Carneiro Beleza, (ii) Francisca Idalina Barros de Oliveira e (iii) Kênia Ferreira de Oliveira, optaram por não realizar apresentação, mas entregaram suas narrativas escritas. A seguir, são descritos excertos das narrativas (auto)biográficas dos acadêmicos de Letras e todo o aprendizado que é possível observar a partir de seus relatos.

\section{Narrando o enxergar-se Autor da própria História dos licenciandos}

Quando abordamos o enxergar-se autor da própria história é plausível informar que autor é todo aquele que se transforma em enunciador, através da singularidade da própria escrita, que dissemina o caráter histórico e social da sua condição, manifestando a coerência entre o vivido e o escrito, o que repercute na sua relação consigo, com o outro (leitor) e com o mundo (SANTOS, 2017, p. 166).

Esse contexto é enfatizado por Souza (2011, p. 213) ao estabelecer o entrecruzamento entre vida, profissão e narrativa com as relações territoriais e de poder,

[...] na medida em que remetem o sujeito a viver sua singularidade, enquanto ator e autor, investindo em sua interioridade e conhecimento de si e estimulando questionamentos sobre suas identidades, reveladas nas escritas do eu. [...] Trajetórias de vida e fragmentos biográficos articulam-se através de ações coletivas, aprendizagem informal e experiências sociais como constitutivas das culturas, identidades, subjetividades e diversidades dos sujeitos em seus territórios de vida-formação.

Escrever e refletir sobre si é tarefa sugerida há vários anos por estudiosos da formação de educadores como uma experiência que pode se configurar como transformadora da prática pedagógica. [...] Essa reflexão sobre si mesmo possibilita a transformação do sujeito que escreve ao passo que este desconstrói a sua vida, para reconstruí-la, através da atribuição de novos sentidos (SOUZA; TAVARES; NASCIMENTO, 2012, p. 168).

Foi possível identificar nas narrativas dos licenciandos suas origens humildes, na periferia das cidades ou na zona rural; a importância que familiares (pais e avós) tiveram no incentivo aos estudos e na necessidade de investimento na Educação para garantir um futuro de qualidade, na maioria das vezes, educando 


\section{Eteducitec \\ ISSN: $2446-774 X$}

através do trabalho, especialmente na agricultura e incentivando-os frequentarem a escola.

Para garantir a privacidade dos cursistas será utilizada na identificação das narrativas as siglas Colab1 a Colab8 (atribuindo aos concluintes a designação de Colaborador).

[...] Fui criado pelos meus avós. Minha mãe biológica me deu para eles me criarem quando tinha dois anos. [Meus avós] eram pessoas simples, com pouca escolaridade, mas de uma garra sobrenatural. Comecei a trabalhar com eles na agricultura. Quando tinha seis anos, me levaram para o plantio de mandioca para me ensinarem como 0 trabalho dignifica o homem. (Colab2).

[...] Sou de família humilde, há poucas pessoas formadas na minha família e sempre tivemos em nossa família que a educação é alicerce, é ainda, unívoca válvula de escape, isto é, a educação significa e significará emancipação e ascensão social e mesmo realizações individuais. (Colab3).

[...] Minha mãe e meu pai foram e ainda são pessoas fundamentais para que eu siga com êxito minha vida estudantil. Filhos de pais analfabetos e pessoas com "pouco saber" (em relação aos livros) eles me incentivaram e me incentivam de todas as formas para que eu busque e consiga uma vida melhor que a deles e dos meus avós, através de todo conhecimento possível. (Colab4).

[...] Foi nessa localidade [Santa Cândida, município de Lábrea] que dei meus primeiros passos ao se por de pé, como também no ensinoaprendizagem, comecei a frequentar a escolar com sete anos de idade, e o meu primeiro professor tinha apenas a $8^{a}$ série e, mesmo assim, foi um dos grandes responsáveis pela minha alfabetização. [...] Meus pais sempre me incentivaram a ir à escola e [...] mesmo indo ajudar meu pai a plantar, limpar e colher o feijão e roça, ele sempre largava o serviço a tempo de que eu e os outros filhos pudesse ir a escola. (Colab5).

[...] Falando da minha educação primária, posso lembrar-me as diversas dificuldades que meus pais enfrentavam para me deixar na escola, pelo fato de eu ser muito apagado a eles. Não gostava de escola, nem queria estar naquele lugar. Com o tempo fui me acostumando a conviver em meio aos colegas e professores [...]. Passaram fazer parte da minha vida, e de alguma forma já estava gostando do espaço escolar. (Colab6).

Comecei a estudar com 6 anos de idade. Meu avô paterno era o meu professor e foi um dos grandes incentivadores para a minha vida estudantil e também um dos maiores influenciadores por eu está aqui hoje. Aprendi com ele a gostar dos livros. (Colab7).

A trajetória acadêmica dos cursistas é permeada a partir das vivências na Educação Básica (Ensino Fundamental e Médio), primando inclusive pela mudança de contextos (ou de cidades) para alcançar o objetivo de galgar através dos estudos a construção de uma vida diferente daquela que os pais e/ou responsáveis enfrentaram.

Lembro-me vividamente como foi meu primeiro dia de aula. Dia muito chuvoso. Meu pai foi me deixar. Minha bolsa era "um saco de bolacha do Braz". [...] Esse dia se tornou inesquecível e a escola se chamava SUDHEVEA. Já comecei a estudar tarde. Tinha 8 anos e meu pai tinha medo que eu fosse para a escola sozinho [...]. (Colab2). 


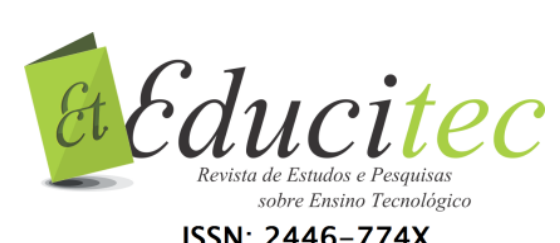

Desde a minha infância a educação sempre se fez presente e em primeiro plano na minha vida, a partir de muito cedo eu já tinha meus cadernos (apesar de só saber fazer rabiscos), ainda tenho uma memória viva da minha primeira letrinha feita: meio torta, sem jeito e miúda. Eu não conhecia o alfabeto ainda, mas algo dentro de mim me dizia que era uma letra. Fiquei eufórica! (Colab4).

Depois de cursar o Ensino Fundamental na zona rural, era momento de dar um passo à frente e continuar caminhando rumo ao Ensino Médio.[...] Migrei para a cidade e fui morar com minha avó materna [...] O primeiro ano nesse novo ambiente social e longe da família foi muito difícil de suportar. O ano era 2011 e a Escola se chamava Balbina Mestrinho. O primeiro dia de aula foi desconfortável por não conhecer ninguém e achar que só porque eu estava vindo do interior todos os alunos daquela sala saberiam mais do que eu. Estava totalmente errado [...] Somos nós que criamos e alimentamos os monstros com pensamentos e ideias falsas. [...] Nesse mesmo ano recebi um certificado de melhor aluno da turma. [...] Aliás, entreguei o certificado para minha mãe. Naquele momento deu pra ver a alegria estampada no seu rosto [...]. (Colab5).

[...] Aos doze anos nos mudamos para a sede do município [PauiniAM] expulsos pela enchente. No começo tudo foi muito difícil, desde a adaptação até as dificuldades financeiras. [...] Terminei o Ensino Fundamental aos 15 anos, apesar de atrasada, era muito dedicada. [...] Quando estava no segundo ano do Ensino Médio engravidei da minha primeira filha. Aos 17 anos ia ser mãe sem nenhuma estrutura psicológica e totalmente dependente dos meus pais. Mas no ano seguinte terminei o Ensino Médio e já comecei a trabalhar como Monitora em uma creche municipal [...]. (Colab7).

Em 2001, com o objetivo de interiorizar o Ensino Superior e constituir mão-deobra local para desenvolver os municípios do interior, o Governo do Estado do Amazonas inaugura a Universidade do Estado do Amazonas - UEA. Estabelece então a expectativa de um futuro promissor [profissionalização, desenvolvimento pessoal, emprego, sonhos, possibilidades] inclusive para os estudantes de Lábrea e região do Purus, bem como aos colaboradores deste trabalho ao disponibilizar o curso de Licenciatura em Letras, a partir de 2015. Nas transcrições a seguir, vislumbramos as expectativas construídas, as dificuldades encontradas e os sonhos que se concretizam no constante caminhar.

Cursar Letras pra mim foi um desafio [...] Quando comecei me senti meio perdido. Ao fazer minha primeira avaliação deu vontade de desistir. [...] Comecei a gostar pelo prazer de buscar conhecimento e tentar mudar o contexto ao qual estou inserido [...]. (Colab2).

Uma tia minha que estava fazendo Pedagogia na UEA informou-me da aprovação, e neste momento senti uma alegria imensurável, inexplicável. Senti ainda vontade de chorar [...] O curso era a concretização de tantos esforços, meus e de minha mãe. [...] Pretendo exercer sim a profissão de professor e como seria transformador se essa profissão tivesse o respeito que lhe é devido, mediante sua nobreza. A nobreza de formar cidadãos e porque não de possibilitar realizações de sonhos, porque só a Educação é capaz de formar cidadãos e realizar sonhos. (Colab3).

Uma coisa interessante foi quando fui me inscrever para o vestibular da UEA. Tinha duas opções: Letras e Geografia. Fiquei pensando um pouco e lembrei da história que minha professora de Matemática tinha 


\section{Educitec \\ ISSN: 2446-774X}

contado sobre a sua escolha para Graduação. Sua matéria preferida era Português e detestava Matemática. Ela acabou escolhendo justamente Matemática porque viu a oportunidade de gostar e absorver conhecimentos naquela área; e por sinal, ela tinha grande domínio na Matemática. Inspirado em sua história não deu outra: já que a matéria na qual tinha menos afinidade era Português, optei por conhecer o Curso Licenciatura em Letras, objetivando a produção magnífica de textos, como também aprimorar o vocabulário oral e consequentemente gostar da Língua Portuguesa. (Colab5).

Ainda em 2014 saiu o Edital para o Vestibular da UEA - acesso 2015. Decidi me inscrever, mas dessa vez foi dedicação total. Eu tinha que ser aprovada. Era como se fosse a minha última chance. Graças a Deus fui aprovada. No momento que soube foi uma euforia: um misto de felicidade e medo. Eu tinha que sair do conforto familiar e passar a morar em uma cidade na qual eu não conhecia ninguém. No entanto, estava decidida e pude contar mais uma vez com o apoio de toda minha família. (Colab7).

\section{Considerações para outros (per)cursos}

Diante de todo o exposto neste trabalho, foi possível realizar algumas ponderações. Dentre elas a importância que o Produto Educacional ora apresentado teve para o crescimento pessoal e profissional deste pesquisador, e o direcionamento para a compreensão da necessidade do enxergar-se autor da própria história, a partir dos episódios marcantes da minha vida pessoal, acadêmica e profissional, em conformidade com as vivências e experiências advindas do percurso investigativo no Mestrado Profissional em Ensino Tecnológico do IFAM campus Manaus Centro. Isso se dá devido ao entendimento de que outros atores deveriam vivenciar essa experiência, como forma de reconhecer que "[...] o sentido que damos à nossa carreira [pessoal, acadêmica e profissional] é compreendido através das histórias de nossas vidas como pessoa e professores/as" (SOUZA; TAVARES; NASCIMENTO, 2012, p. 167), o Produto Educacional foi aplicado a dezessete dos 36 acadêmicos do curso de Licenciatura em Letras da Universidade do Estado do Amazonas (UEA), em Lábrea.

Outra ponderação refere-se à aplicação, que foi realizada conforme os Planos de Curso e Roteiros de Estudos, porém, de acordo com as especificidades da turma foi necessária a alteração do roteiro para que o (Per)curso fosse direcionado à construção de narrativas (auto)biográficas e realização de um Colóquio de Narrativas como atividade final do curso, em detrimento da construção de um Portfólio Online, conforme programa original do curso, o que não foi um revés, mas, uma adaptação de (per)curso, o que é inclusive aconselhada pelo autor, dadas as peculiaridades dos cursistas.

Uma terceira ponderação refere-se ao fato de que nosso Produto Educacional, que foi um curso de curta duração de $40 \mathrm{~h}$ intitulado "(Per)curso de autoria: enxergando-se autor da própria história", cumpriu seu objetivo de direcionar o cursista a "[...] compreender a importância do percurso de autoria para 0 ressignificar das práticas pedagógicas, a partir das reflexões dos episódios marcantes, enxergando-se autor da própria história", temática que é fundamental 


\section{Ed Educitec \\ ISSN: 2446-774X}

para estes concludentes de Licenciatura em Letras tornem multiplicadores desta temática e posteriormente aperfeiçoem novos estudos, haja vista que este também possui suas incompletudes e a necessidade de novos debates, adaptações, geração de novos conhecimentos.

Decorrente do exposto, enxergar-se autor da própria história é "[...] dizer a sua própria palavra, compreender o seu mundo, fazer e escrever a sua própria história. Trata-se de um movimento que produz um conhecimento alicerçado da vida, na experiência, que é em si singular, mas produzido na relação com o outro, com o mundo, neste caso com a educação, a escola e a constituição da docência na pessoa (ARENHALDT; MARQUES, 2010, p. 20), o que ficou evidente durante este (per)curso com os licenciandos em Letras da UEA/Lábrea.

\section{Referências}

ARENHALDT, R.; MARQUES, T. B. I. (Org.). Memórias e afetos na formação de professores. Série: Cadernos PROEJA - Especialização - Rio Grande do Sul. Pelotas, RS: Editora Universitária/UFPEL, 2010.

CUNHA, R. B. As memórias nos clássicos e nossas clássicas memórias. In: PRADO, G. do V. T.; SOLIGO, R (Org.). Porque escrever é fazer história: revelações, subversões, superações. Campinas, SP: Editora Alínea, 2007.

GHEDIN, E.; FRANCO, M. A. S. Refletindo sobre pressupostos da pesquisa em Educação. s/d. p. 1-17.

GONZAGA, Amarildo Menezes; ANIC, Cinara Calvi. A Fenomenologia como pressuposto investigativo. 2017.

GONZAGA, Amarildo Menezes (Org.). Formação de professores no Ensino Tecnológico: fundamentos e desafios. Curitiba: Editora CRV, 2015. p. 285293.

RICOEUR, P. Tempo e narrativa. Campinas, Papirus, 1994.

SANDÍN ESTEBAN, Maria Paz. Pesquisa Qualitativa em Educação: Fundamentos e tradições. Tradução de Miguel Cabrera Porto Alegre, RS: AMGT Editora, 2010.

SANTOS, Antonio Paulino. Percursos de autoria de Professores do Ensino Tecnológico. 2017. 172 f. Dissertação (Mestrado Profissional em Ensino Tecnológico) - Instituto Federal de Educação, Ciência e Tecnologia do Amazonas - IFAM campus Manaus Centro, Manaus-AM, 2017.

SANTOS, Antonio Paulino; GONZAGA, Amarildo Menezes. (Per)curso de autoria: enxergando-se autor da própria história. Produto Educacional da dissertação: Percursos de Autoria de Professores no Ensino Tecnológico Instituto Federal de Educação, Ciência e Tecnologia do Amazonas - IFAM campus Manaus Centro, Manaus-AM, 2017.

SOUZA, E. C. Territórios das escritas do eu: pensar a profissão - narrar a vida. Revista Educação. Pesquisa (auto)biográfica, experiência e formação. V. 34, n. 2. Porto Alegre: EDIPUCRS, 2011. 
ISSN: 2446-774X

SOUZA, F. C. S.; TAVARES, A. M. B. N.; NASCIMENTO, A. S. G. Formação de Professores: As narrativas de graduandos da Licenciatura em Matemática do IFRN/Mossoró. Revista Holos, v. 2, n. 28, p. 166-173, 2012.

Submetido em 20/08/2018.

Aceito em 20/02/2019.

(C) $(1)$ 